\title{
Limb Ischemic Preconditioning for Open Heart Surgery in Infants
}

\author{
Oc Bahar $\cdot$ Duman Ates $\cdot$ Wenwu Zhou
}

Published online: 13 February 2011

(C) Springer Science+Business Media, LLC 2011

We read the inspiring article by Zhou and colleagues in the January 2010 issue of Pediatric Cardiology [1]. We consider this study to be a fundamental basis for future research because it shows that remote limb ischemic preconditioning is a simple, noninvasive technique that also can be used for infants. But we are concerned about the safety of the cuff pressures used during remote ischemic preconditioning.

In the current study, the authors inflated the pressure cuff to $240 \mathrm{mmHg}$ for infants. In previous similar adult study protocols, cuffs have been inflated to 200 or $40 \mathrm{mmHg}$ above the patients' actual upper arm blood pressure $[2,3]$. Tourniquet pressures may cause complications such as soft tissue blisters, burns, rashes, abrasions, nerve-related injuries, and muscle injuries [4]. Lieberman et al. [5] recommended that a cuff pressure of $50 \mathrm{mmHg}$ above systolic blood pressure is sufficient to provide limb ischemia in pediatric patients. We believe future studies should use lower cuff pressures to minimize pressurerelated tissue damage in infants.

\section{Reply}

We appreciate the comments from Oc Bahar and colleagues. How to perform limb ischemic preconditioning is

O. Bahar $(\bowtie) \cdot$ D. Ates

Selcuklu Faculty of Medicine, Anesthesiology and Intensive Care, Selcuk University, Konya, Turkey

e-mail: baharoc@selcuk.edu.tr

W. Zhou

Department of Cardiothoracic Surgery, Hunan Childrens

Hospital, Changsha 410007, China

e-mail: acrophober@163.com; mark037100@163.com a key point in our study. We inflated the pressure cuff to $200 \mathrm{mmHg}$ in previous studies. This pressure decision was based our belief that the maximum pressure not leading to pressure-related complications should be used. During the clinical study, we did encounter mild skin injuries lasting for the first days of preconditioning and resolving a few days later. In addition, we found that a pressure of $200 \mathrm{mmHg}$ is sufficient to cause a protective effect for preconditioning. Currently, we use pressure of $200 \mathrm{mmHg}$ for arm ischemic preconditioning and a pressure of $240 \mathrm{mmHg}$ for leg ischemic preconditioning.

\section{References}

1. Lieberman JR, Staheli LT, Dales MC (1997) Tourniquet pressures on pediatric patients: a clinical study. Orthopedics 20:1143-1147

2. Tredwell SJ, Wilmink M, Inkpen K, McEwen JA (2001) Pediatric tourniquets: analysis of cuff and limb interface, current practice, and guidelines for use. J Pediatr Orthop 21:671-676

3. Venugopal V, Laing CM, Ludman A, Yellon DM, Hausenloy D (2010) Effect of remote ischemic preconditioning on acute kidney injury in nondiabetic patients undergoing coronary artery bypass graft surgery: a secondary analysis of 2 small randomized trials. Am J Kidney Dis 56:1043-1049

4. Wagner R, Piler P, Bedanova H, Adamek P, Grodecka L, Freiberger T (2010) Myocardial injury is decreased by late remote ischaemic preconditioning and aggravated by tramadol in patients undergoing cardiac surgery: a randomised controlled trial. Interact Cardiovasc Thorac Surg 11:758-762

5. Zhou W, Zeng D, Chen R, Liu J, Yang G, Liu P et al (2010) Limb ischemic preconditioning reduces heart and lung injury after an open heart operation in infants. Pediatr Cardiol 31:22-29 